\title{
A Comparison Between an Indonesian and an English Journal Published in Indonesia
}

\author{
Endro Dwi Hatmanto ${ }^{1 *}$ \\ ${ }^{1}$ English Education Department, Universitas Muhammadiyah Yogyakarta \\ *Corresponding author. Email: endrodwihatmanto@umy.ac.id

\begin{abstract}
One of the challenges faced by Indonesian writers in writing the research paper is writing the introduction section. Different from other forms of writing, the Research Article Introduction (RAI) section in the academic research articles have specific structure, formats and convention. The previous studies suggested that, for most students, writing research articles seemed more demanding for writers since they had to struggle with the structural and linguistic aspects of writing, making this ability their unique experience. Despite several studies investigating the writing of the research introduction in research paper, the ones which compare the introduction writing across different languages were still rare. The current study is focused on exploring one genre of academic writing done by 20 Indonesian and foreign writers of an Indonesian and an English journal using the CARS (Creating a Research Space) framework proposed by Swale. According to Swale, introduction in the research paper employs three moves comprising establishing the territory, establishing a niche and occupying a niche. The data revealed that an explicit gap statement was often not found in both Indonesian and English research introduction. This shows that the rhetorical styles of the Indonesian and English RAIs written by Indonesian writers are very different from those in English RAIs as suggested by Swales.
\end{abstract}

Keywords: Research article introduction, creating a research space, rhetorical styles

\section{INTRODUCTION}

Recently, there has been a spate of interest in the study on the rhetorical structure of the academic research articles [1] [2]. Different from other forms of writing, academic research articles have to be structured using certain norms, criteria, convention and rhetorical format [3]. A rhetorical model was described by Swales as a rhetorical move, referring to specific communicative roles performed by each text [4]. In general, the academic writing framework involves an abstract accompanied by introduction, analysis of literature, methodology, research results, discussion of research results and conclusion. As pointed out by Tengku Mohd Maasum and Abd Aziz [5] and Cheung [6], the introduction in academic papers helps to open the paper, draw readers' interest and convey the significance of the study. In other words, the introduction serves as the presentation and the topic explanation of the writers' stand in their writing.

Located after an abstract and functioned to draw readers' attention to read the whole article, introduction section becomes the most important section in a research article; hence, this section should be persuasively and convincingly written [7] [8]. An uninteresting or unimportant introduction may cause readers to discontinue reading the article and make editors of a research journal reject it. In the same vein, Belcher states that a RA's introduction section is intended to provide readers with sufficient information in order to understand the writers' argument [9]. Swales and Feak also state that the RAIs are aimed at justifying the importance of the article and motivating readers to read it [10]. According to Safnil, however, authors from various disciplines although writing in the same language may write this section differently due to different research practices and academic writing style [8].

The current study is focused on exploring one genre of academic writing done by 20 Indonesian writers of an Indonesian and an English journal using the CARS framework proposed by Swale [4]. According to Swale, introduction in the research paper employs three moves comprising establishing the territory, establishing a niche and occupying a niche. As Swale suggests, the author sets the context for his or her research in the first move (establishing a territory), thus providing the necessary background on the subject [4]. This move consists of one or more steps comprising claiming centrality, generalizing topics and reviewing prior research items. In the second phase (establishing a niche), the writer claims that the current research has an open 'niche,' a room that needs to be filled up by additional research by using one of the following steps: counterclaiming, suggesting distance, raising questions and counting a tradition. The writer transforms the niche formed in Move 2 into the research space he or she will fill in in the third move (occupying a niche). 
As revealed in the studies carried out by Keong and Mussa [11], Pineteh [12], Abdulkareem [13] and Giridharan [14], the difficulties faced by students in writing reports of academic research papers pertained to insufficient amount of vocabulary, grammatical errors and problems in structuring and organizing ideas into sentences and paragraphs. However, as Chandrasegaran asserts, studies factors such as a lack of vocabulary and grammatical errors as the difficulty students have in writing a research report constitute a partial spectrum of overall challenges students face [15].

Different from research articles in English, fewer studies have been conducted on how Indonesian writers organize their information or ideas in Indonesian RAIs. Among the few studies are from Adnan [16], Mirahayuni [17] and Safnil [8]. Such genre-based studies seek to learn how Indonesian writers explain their research topic and project in their RAIs written in multiple disciplines either in Indonesian and/or English. Studying the rhetorical style of RA introductions written in Indonesian by Indonesian authors in fields of education, psychology and economics, Safnil [8] found that in the corpus of his research, there were differences in terms of moves and steps between the discourse style of the RAIs in those three disciplines and the RAIs in English as proposed by Swales [4] in his CARS model.

Despite several studies investigating the writing of the research introduction in research paper, the ones which compare the introduction writing across different languages were still rare. e research introductions tend to follow a pattern different from that of the CARS model proposed by Swale, while in English the research introduction follow it closely.

The CARS model is employed in the current exploratory study to compare the structural organization of research article introduction in a Bahasa Indonesia journal and an English journal published in Indonesia in their rhetorical structure, taken from the same field of research, namely language study. By concentrating on the same field of interest, it is believed that cross-cultural differences in rhetorical organization can be more articulated. As SalagerMeyer pointed out, the findings of this type of study will lead to the understanding of problems that writers may face in nonEnglish speaking countries as they attempt to publish in international journals [18].

\section{DATA AND METHOD OF ANALYSIS}

This exploratory study used the corpus comprising 20 research article introductions taken from two international journals in the area of language teaching: An Indonesian journal (INJ) and an English journal (ENGJ) published in Indonesia. Both journals are peer-reviewed and the publication was started in 2000 .

The ten papers chosen from the INJ were in Indonesian language and were published in 2019 and 2020. Documents more recent than 2020, which determined the time chosen for the corpus, were not publicly available. The first 10 papers published in Indonesian were picked, beginning with the most recent publicly accessible topic and went backwards. The 10 articles from ENGJ published in the year 2020 were selected to match the time frame. The special issues in both journals were omitted during the selection process.

Swales' CARS model was used for analysing the structural organization of the RAIs [4]. For identification of moves and steps in the RAIs sections, the procedures proposed by Dudley-Evans was employed including identifying and analysing the title, sub-title, key terms, discourse clues and communicative units from the text [19].

All of the INJ writers were affiliated with Indonesian universities, which came as no surprise given that INJ was a national publication, and papers on teaching Bahasa Indonesia were not usually published in English. On the other hand, labelled as an International journal, the authors of the ENGJ's affiliated with both Indonesian and overseas universities. Specifically, in this journal five of the 10 authors were Indonesians while the other five came from different overseas universities including the Philippines, Algeria, Jordan and Iran.

The next paragraph shows the findings from the analysis using the CARS model. The move structure of most of the papers in both the INJ and the ENGJ demonstrated considerable divergence from the CARS model's proposed structure.

\section{FINDINGS}

To begin with, five of the seven INJ introductions included only movements 1 and 3, so they did not have a move 2 (i.e. they do not establish a niche). One introduction (INJ2) only contained a single move. While one introduction followed 3 moves even though it was no arranged subsequently, namely INJ4 which employed M1, M3, M1. Thus, none of the INJ introductions followed a strict M-M2M3 sentence as proposed in the CARS model. In fact, an introduction, namely INJ 10 followed the complete moves from move 1 to move 3. However, the first move appeared again after the move 3 . After outlining purposes of the article, the next following paragraphs explained the topic generalization which was supposed to be appear only in the move 1 . The only sequence which was repeated is M1- M3 type, which occurred five times. In summary, RAIs in the INJ did not seem to follow a pattern in the organization of the rhetorical moves although there seemed to be a preference for the M1-M3 type. In this type of the structural organization, the authors established a territory by giving background information and making topic generalizations.

With regard to the rhetorical structure used in the INJ, especially the strategies used by the writers in establishing the 'territory' (move 1), none of them used move 1 (claiming centrality). In terms of move 2, two RAIs of INJ9 and INJ10 established the 'niche' of the research. For illustration, the writer of the INJ9 conducted a study on the development of interactive-communicative games technique of speaking for 
beginner class for foreigners studying Bahasa Indonesia. After explaining several previous studies in this area, the writer pointed out the gap by stating that the previous studies emphasized more on the development of learning materials, learning methods and the media but less on the development of learning techniques. Similar strategy in establishing the 'niche' by presenting the research gap was also done by the writer in INJ10. In terms of the occupying the niche (move 3), most of the RAIs (eight) in the INJ employed this move despite different steps taken.

Four articles of the ENGJ, on the other hand, follow the M1-M2-M3 sequence; four others contain move 1 and move 3 while two articles contain a repetition of one move. Regarding the rhetorical structure incorporated in the ENGJ concerning the strategies used by the writers in establishing the 'territory' (move 1), only ENGJ2 incorporated the complete steps, from step 1, step 2 to step 3 (claiming centrality, making topic generalization and reviewing items of previous research). Most of them (nine RAIs) presented topic generalization in order to establish the territory. Concerned with establishing the 'niche' (move 2), four RAIs which adopted move 2 presented the research gap of the previous studies.

Despite the inclusion of the move 1, one article, namely ENGJ3, employed an unclear move 1, establishing territory. This article focuses on investigating the school achievements based on the gender differences from the perspectives of teachers.

The findings suggest that less than $50 \%$ of the introduction of both INJ and ENGJ comply with the complete move 1 to move 3 as suggested in the CARS model. Specifically, only two of the 10 introduction in INJ incorporated the complete moves while four journals out of 10 in the ENG had the complete moves. In addition to this, moves 1 and 3 seemed to be the most favourite moves incorporated in the INJ as six articles used these. Fewer than INJ, there were four introductions in the ENGJ which used this move although these moves seemed to be the most frequently used.

In terms of number, however, it can still be said that ENGJ had more introductions (four) complying with the CARS models than INJ (two). It is important to note that both journals specialized in the same subfield of the language teaching. This was supported not only by both the names of these journals and their similar editorial policies. Even though English journals reaches a wider international readership given the status of English as a lingua franca [20], both journals can be considered as having the similar stage of maturity as they started publication in the same year. In this regard, the difference between established fields and emerging fields proposed by Samraj cannot probably explain the distinction between the introductions in the INJ and ENGJ in this study [21]. It appears that the differences found were related to the inclination of the international rules in the academic writing.

\section{DISCUSSION}

The first striking finding was the absence of the claiming centrality step of the move 1 in both INJ dan ENGJ. In the CARS model proposed by Swale [4], the first and vital step of the move 1 (establishing territory) was claiming centrality. Using this step, a writer asks the audience or the discourse community for the paper to accept that the study which will be reported is part of a significant, lively, or well-established research field. The subsequent steps which seemed to be the common pattern used by the writers in both the INJ and ENGJ in writing RAIs were establishing the research field, justifying and announcing the current research.

The next step taken by the writers was justifying the present research and announcing the present research. This finding confirms Safnil's study on the rhetorical structure of the Indonesian authors in writing RAIs [8]. His study revealed the RAIs written by Indonesian writers usually employed several steps, namely establishing shared knowledge background, establishing the research field, justifying the present research, announcing the present research

The second prominent finding is the pervasive absence of the move 2 in both INJ and ENGJ. In total there were eight introductions in INJ which did not contain this move while there were six introductions in ENG which did not contain the same move. Indonesian writers, as Arsyad and Arono revealed in his study, tend to use the following strategies in justifying the study: 1) indicating a gap in previous study; 2) claiming that the topic has never or rarely been explored; 3 ) claiming that the topic is necessary to investigate and 4) claiming interested in investigating the topic [1]. The steps taken by Indonesian writers as revealed in Arsyad' studies seemed to be found in the current research.

Interestingly, five foreign writers, two from Algeria and others from Jordan, Iran and the Philippine, also did not present research justification with the possible steps in the 'establishing a niche' move including counterclaiming, indicating a gap, question rising and counting a tradition. This suggests that despite its position of international English journal, the ENGJ did not include the 'establishing a niche' as an important step for writers. Hence, even 'international' writers still seemed to follow 'Indonesian' style in writing the RAIs.

Other studies that looked at RAIs in languages other than English have found a similar finding in terms of the absence of the Move 2. For example, Jogthong revealed that there was an absence of Move 2 in $45 \%$ of the Thai articles studied [22] while in Ahmad's study 35\% of the corpus of Malay RAIs lacked of Move 2 [23]. Hirano also found that $70 \%$ of the RAIs in Portuguese did not contain this move, while only $10 \%$ of those in English lacked it [2]. In this current study 80 $\%$ of the RAI's in Indonesian did not contain this move, while $60 \%$ of those in English lacked it.

Literature has discussed a few potential explanations concerning this apparent lack of need to establish a niche for one's researcher or to justify research. For example, Citing Najjar [24], Jogthong said authors have less pressure to publish in smaller discourse groups, which are more 
representative of developing countries, and therefore need not be competitive for a research space [22]. From my knowledge of Indonesian academic context, that does not seem to apply, particularly in regard to the pressure for publication. As an illustration, a cursory look at the research provided by the Indonesian Government reveals that researchers have been provided with a large amount of money.

A more likely possibility for the present study relates to solidarity with the local research community, as discussed in the study done in Taylor and Chen in which they contrasted Anglo-American and Chinese RAIs [25]. Chinese scholars, according to Taylor and Chen found it discomfort able in articulating weaknesses and gaps of the previous studies [25]. Similarly, according to the Rezende and Hemais, the stage of establishing a niche was often avoided by the Brazilian writers as this was considered as ignorance invoking a negative attitude from other researchers in the scientific community [26].

The research justification done by Indonesian writers as in the case of INJ and ENG by presenting the writers' interest in conducting the research on the issue may be perceived as being personal or subjective by international journal readers because these writers conduct a certain study only because they find it important or necessary not because there is gaps of knowledge in the literature as commonly explained in English RAIs [1]. In addition, Arsyad pointed out that very few Indonesian writers (only 36 out of 400 or $9 \%$ ) used the gap found in previous research in their studies as it is usually found in English RAIs [1].

This occurs because Indonesian authors prefer not to negatively evaluate or critique other authors' writing. As stated by Keraf, it is considered culturally impolite to critique other people especially those who are older and have higher economic and social status [27]. However, such a consideration is regarded as not an ideal attitude as in the context of academic writing, expressing the truth which involves the evaluation of others' writing is unavoidable. Likewise, Adnan suggested that the avoidance of critiquing others' academic writing is regarded a national noble value by Indonesian authors in both social and hard sciences since doing so can lead to worsening relationship [16].

In the similar vein, Soeparno et al., explained that traditional and subjective thinking is still found in the Indonesian academic atmosphere [28]. Such a thinking style is characterized by easily trusting what other people claim without evaluation. However, as Soeparno et.al., suggested, since Indonesia has been transforming to industrial society, more and more scientists begin to investigate and testify the truth proposed or claimed by other writers in their academic writing.

The above statements are in congruent with those of ethnographers including Saville-Troike who say that, different from Western cultures, Eastern peoples such as Korean, Chinese and Japanese and possibly Indonesian find group unity and collective interest more relevant [29]. Preferring keeping silence over criticizing others in order to maintain harmony, Indonesian academic authors appear to adopt this thinking style in their academic writing.

\section{CONCLUSION}

The CARS model was found to be useful as a tool to analyze and compare the differences of RAIs written in both Indonesian and English. In general, it seems to be the case that Indonesian and foreign authors writing in both English and Indonesian journals published in Indonesia tend to favour solidarity and avoid confrontation with local discourse community. As a result, an explicit gap statement is often not found in both Indonesian and English RAIs. Instead of justifying the present research, the Indonesian writers in both journals attempts to establish shared knowledge to begin their RAIs. Additionally, personal reasons were often utilized in justifying their research topics. The current study found that very few Indonesian writers and so were the foreign writers writing the English RAIs in the English journal published in Indonesia justify their research by presenting the gap in the previous studies. This shows that the rhetorical styles of the Indonesian and English RAIs written by Indonesian writers are very different from those in English RA introduction as suggested by Swales [4]. Readers from languages other than Indonesian must accept that this is a common style acceptable in Indonesian RAIs; however, if Indonesian authors use this rhetorical style when writing an RA in English to be published in an international journal, it will be problematic and may cause the RAIs to be rejected.

An important suggestion needs to be addressed here that Indonesian RA writers must modify their RAIs rhetorical styles especially when justifying their research topic or problem when writing in English and willing to publish an article in reputable international journals. This might lead to the improved possibility of the article to be accepted in a desired international journal. Thus, adjusting to the rhetorical style commonly found in international journals is an important strategy for the Indonesian RAIs writers in order to increase the chance of being accepted in journal articles in an international journal.

\section{REFERENCES}

[1] S. Arsyad \& M. Arono, Journal of Multicultural Discourses. 11, 3 (2016).

[2] L. Hirano (2009), English for Specific Purposes. 28 (2009).

[3] Margaret Cargill and Patrick O'Connor, Writing Scientific Research Articles Strategy and Steps (John Wiley \& Sons Ltd, 2009).

[4] J.M. Swales, Genre analysis: English in academic and research settings (Cambridge University Press. 1990).

[5] T.M. Maasum and A. Aziz, Procedia - Social and Behavioral Sciences. 502 (2014).

[6] Y.L Cheung, Understanding the writing of thesis introductions: An exploratory study (Longman, 2012).

[7] J, Swales, \& H. Najjar, Written Communication. 4 (1987).

[8] Safnil, Rhetorical structure analysis of the Indonesian research articles (The Faculty of Languages and Arts 
of the Australian National University, Canberra Australia, 2001).

[9] D.D. Belcher, Journal of Second Language Writing. 18, 4 (2009).

[10] J. M. Swales and C. B. Feak, Academic writing for graduate students (The University of Michigan Press, 1994)

[11] Y.C. Keong, \& I.H. Mussa, International Journal of Education and Research. 3, 6 (2015).

[12] E.A. Pineteh, International Journal of Higher Education. 3, 1 (2014)

[13] M. Abdulkareem, Theory and Practice in Language Studies. 3, 9 (2013).

[14] B. Giridharan, US-China Education Review. 6 (2012).

[15] A.L. Chandrasegaran, Asian Journal of English Language Teaching. 10, 91 (2012).

[16] Z. Adnan, Strategies for oral communication between superiors and subordinates at the local government of Yogyakarta (State University of Malang, 2014).

[17] N.K. Mirahayuni, Investigating textual structure in native and non-native English research articles: strategy differences between English and Indonesian writers (The University of New South Wales, Australia, 2002)

[18] F. Salager-Meyer, Journal of English for academic purposes. 7, 2 (2008).
[19] A. Dudley-Evans (1994), Advances in Written Text Analysis. 2, 11 (1994).

[20] A. Duszak \& J. Lewkowicz, Journal of English for academic purposes. 7, 2 (2008)

[21] B. Samraj, English for Specific Purposes, 24, 2 (2005).

[22] C. Jogthong, Research Article Introductions in Thai: Genre Analysis of Academic Writing (West Virginia University, 2001).

[23] U.K. Ahmad, Culture and styles of academic discourse, New York: Mouton de Gruyter, 1997)

[24] H. Najjar H, Arabic as a research language: The case of the agricultural sciences (University of Michigan, 1990)

[25] G. Taylor \& T. Chen, Applied Linguistics. 12, 3 (1991).

[26] P.A. Rezende \& B. Hemais, the ESPecialist. 25,2 (2004).

[27] G. Keraf, Diksi dan Retorika (Yogyakarta: PT Kanisius, 1992)

[28] H.A.Soeparno, M. Donoseputro, \& A. Sukadana, Pola Berfikir Ilmuwan dalam Konteks Sosial Budaya Indonesia (Airlangga University Press, 1987).

[29] Saville-Troike, Introducing Second Language Acquisition (Cambridge University Press, 1982) 